\title{
INFLUÊNCIA DA VIOLÊNCIA CONJUGAL SOBRE A DECISÃO DE ABORTAR
}

\author{
THE INFLUENCE OF MARITAL VIOLENCE ON THE DECISION TO HAVE \\ AN ABORTION \\ INFLUENCIA DE LA VIOLENCIA CONYUGAL SOBRE LA DECISIÓN DE \\ ABORTAR
}

Vera Lúcia Costa Souza'

Sílvia Lúcia Ferreira²

\begin{abstract}
RESUMO: Os estudos sobre a violência conjugal contra a mulher tem trazido importantes contribuições para o entendimento dos problemas de saúde, aos quais esta população está exposta, em especial os vinculados à atividade reprodutiva. A necessidade de investigar com mais profundidade os nexos entre a violência e o aborto provocado, têm gerado alguns questionamentos, por exemplo: Será que a decisão de abortar surge no ciclo da violência conjugal como um momento de autonomia da mulher ou estas são forçadas a praticar o aborto? Este estudo qualitativo, tem como objetivo caracterizar as manifestações de violência conjugal entre mulheres internadas em situação de aborto provocado, analisando a influência da violência sobre a decisão de abortar. Pretendendo-se com os resultados ampliar a discussão sobre a violência e o aborto dando visibilidade a estes problemas no âmbito dos serviços de saúde. Também possibilita a reflexão das mulheres sobre a situação de violência a que estão submetidas, através da discussão coletiva das suas histórias de vida que refletem vivências de ameaças, desamor, negligência, violência sexual e agressão física
\end{abstract}

PALAVRAS-CHAVE: violência conjugal, aborto provocado, ciclo da violência

\section{INTRODUÇÃO}

A violência contra a mulher no âmbito doméstico tem se manifestado como expressão de desigualdade entre os cônjuges, na qual a mulher não tem controle de sua própria vida e tem freqüentemente como agressor o próprio parceiro. Para Noronha e Daltro (1991) a violência tem como eixo de significação a idéia de força, opressão que se impõe de um pólo sobre o outro, estando associada a idéia do imprevisível, ausência de norma e a um acontecimento sem regularidade ou estabilidade.

Como afirma Pavez (1995) "a violência doméstica é entendida como todo ato que transgrida os direitos e integridade física, psicológica e sexual perpetrada entre os membros da família." Concorda com esta definição Anthony e Miller citado por Gómes (1996, p.6) que conceitua a violência doméstica como: "todo ato cometido dentro da família por um de seus membros e que prejudica gravemente a vida, o corpo, a integridade psicológica e/ou a liberdade de outro dos membros da família".

\footnotetext{
${ }^{1}$ Professora Assistente da disciplina Saúde da Mulher, Criança e Adolescente da Universidade Estadual de Feira de Santana; Mestra em Enfermagem na Atenção à Saúde da Mulher.

2 Profa. Dra. do Departamento de Enfermagem Comunitária da UFBA. Pesquisadora do GEMGrupo de Estudos sobre Saúde da Mulher e do NEIM- Núcleo de Estudos Interdisciplinares sobre a Mulher.
} 
Dentre os tipos de violência doméstica encontra-se a violência conjugal, aquela incidida por parte do cônjuge e se expressa com maior freqüência em espancamentos de mulheres por parte do companheiro, sendo, também, chamada de violência de gênero por ser uma relação de poder que estrutura papéis diferentes, opressão, dominação ou exploração com poder centrado na maioria das vezes, no homem (Saffioti,1994). Esta mesma autora ressalta que a violência integra a organização de gênero pois atribui significado ou seja identidade, valor, status na hierarquia social, aos indivíduos no interior da sociedade regendo comportamento de homens e mulheres.

Estudos sobre a violência de gênero têm comprovado as repercussões sobre a saúde física e mental da mulher (Heise, 1994, 1995).

Em relação à gestação vários autores dentre os quais Heise (1995) e Helton e Mcfarlane (1987) relatam que a violência pode desencadear gravidez indesejada, abortos espontâneos e aborto provocado.

Dados relacionados à violência e aborto no município de Feira de Santana (BA) registram que na Delegacia de Proteção à Mulher (DPM), no período de 1991 a 1998, a maioria das mulheres continuam como vítima vulnerável de seu companheiro: 2.188 queixas registradas em $1991 ; 3.044$ em 1992; 3.017 em 1993; 2.510 em 1994; 1.587 em 1995; 2.496 em 1996; 2.767 em 1997; e 2.100 no primeiro semestre de 1998. Comparando-se os dados de 1997 e 1998 , verifica-se que, neste último ano, o número de estupros evoluiu de 4 para 9 casos, as tentativas de homicídios de 4 para 7 e as lesões corporais de 452 casos para 340.

Com relação ao aborto, um trabalho realizado no período de 1995 a 1996 (correspondendo a 18 meses), demonstra a alta freqüência de aborto em Feira de Santana, com 5.983 admissões para curetagens pós-aborto, representando a segunda causa de internamento obstétrico, incluindo hospitais públicos e privados, com uma proporção de parto/aborto 3;1 nos dois anos consecutivos, com predominância do aborto provocado entre mulheres jovens (Souza, 1998).

Esta pesquisa procura investigar as manifestações de violência conjugal entre mulheres internadas em situação de aborto provocado, buscando analisar a influência deste fenômeno na decisão da mulher pelo aborto provocado.

\section{METODOLOGIA}

O campo de realização da pesquisa foi uma maternidade pública de referência municipal para atendimento à mulher, localizada no município de Feira de Santana-Bahia que desenvolve ações do Programa de Assistência Integral à Saúde da Mulher em ambulatório e unidade de internação. Possui um Banco de Leite humano sendo considerado pela UNICEF, "Hospital Amigo da criança". No período de 1995/1996 foi responsável por $21 \%$ do total da curetagens pós-aborto do Município e uma proporção de um aborto para cada 2 partos. (Souza,1998)

Para o desenvolvimento desta pesquisa foi encaminhada solicitação para a direção do hospital, sendo realizada a coleta de dados após o consentimento. Utilizou-se a entrevista semi-estruturada como instrumento de coleta de dados, tendo sido investigadas mulheres casadas ou em união estável ${ }^{3}$, internadas com história de aborto provocado e que referiram violência conjugal.

\section{RESULTADOS}

Foram entrevistadas 12 mulheres, das quais, buscou-se inicialmente caracterizar o perfil

${ }^{3}$ União estável - Foi considerada neste estudo a união da mulher com o companheiro, a partir de 3 meses de convivência na mesma unidade domiciliar. 
sócio-econômico. Segundo a faixa etária, 25\% encontravam-se entre 15 a 19 anos, $50 \%$ entre 20 a 26 anos e $25 \%$ entre 30 a 33 anos. Quanto à escolaridade, $75 \%$ tinham primeiro grau incompleto; todas possuíam parceiro fixo, sendo $17 \%$ casadas e $83 \%$ amasiadas em união estável com o companheiro. Com relação a trabalho remunerado, $41 \%$ dessas mulheres possuiam renda que variou de menos de 1 a dois salários mínimos e $59 \%$ eram donas de casa, desenvolvendo trabalho doméstico sem renda própria. Todas dependiam parcial ou totalmente de ajuda financeira do companheiro e/ou parentes. Quanto à moradia, 33\% moravam em casa própria e $42 \%$ em casa alugada com companheiro e filhos; com relação à procedência, $75 \%$ das entrevistadas moravam em Feira de Santana, sendo que $50 \%$ na zona urbana, em casas que possuem água encanada, luz elétrica e sistema de esgoto e $25 \%$ moravam na zona rural sem energia elétrica e utilizavam água de cisterna.

As entrevistadas caracterizaram o companheiro como um homem bom, trabalhador, forte, bom pai de família, vaidoso, exigente, provedor da família, socialmente agradável, alegre, calmo e conversador na rua, porém em casa reclama de tudo, é fechado, controlador das suas vidas, não dando satisfação de sua vida social e não compartilha o cotidiano da vida doméstica.

Lagarde (1990) descreve que culturalmente se espera que a mulher deva ser acolhedora, dependente, obediente, compreensiva, pouco complicada, boa e ignorante; o homem deve ser forte, protetor, sábio, trabalhador. Nesta mesma linha, Fucs (1993) assinala que tendo sido educada para depender do homem, a mulher exige deste fortaleza, segurança, capacidade de decisão e não o aceita como um fraco. Esta mesma autora descreve que "os homens mesmo casados, ficam juntos de suas mulheres, porém emocionalmente separados. As relações extraconjugais são usuais e esperadas, servindo-Ihes como prova da manutenção de poder, de sua desejabilidade e capacidade de sedução. Representa também um meio de auto-afirmação, de demonstração pública de sua masculinidade, além de lhes gerar a sensação de que continuam soltos e independentes, sem aprisionamento algum" (Fucs, 1993, p.26-29).

A mulher ao casar mantém uma perspectiva de dedicação ao marido e espera reciprocidade. Porém descobre que em pouco tempo deixa de ser alvo de atenção e desejo, no ambiente social não desfruta da mesma importância que o marido dá aos amigos, trabalho e lazer. Isto Ihe traz sentimentos de frustração e infelicidade. O sentido de felicidade também se modifica com o gênero. Ideologicamente se espera que a mulher encontre a plenitude de felicidade no espaço da família como mãe e esposa sendo esta uma extensão da feminilidade.

Ele é bom, não é muito carinhoso. Ele quer viver livre, sem dar satisfação e não aceita que eu reclame. Ele tem muitos amigos que influencia sua vida. (Entrevistada $8,2)$

Com as pessoas na rua, é uma pessoa alegre, conversador, calmo, mas em casa é grosseiro. Todos os dias sai de casa cinco horas da tarde e só volta meia noite. Não dá satisfação e não quer que eu reclame. (Entrevistada 10, 7)

Ao solicitar para as entrevistadas a definição do que significa violência conjugal, a maioria identifica como sendo violência física praticada pelo companheiro:

Espancamento, controle da vida da mulher, ameaça de morte (Entrevistada 6, 1); É quando a mulher apanha (Entrevistadas 2, 3, 5, 6, 7, 9, 10).

Fica claro nestes discursos que as mulheres não reconhecem estar vivendo em situação de violência sexual ou emocional e definem violência como algo distante de sua realidade. Consideram o domínio e exploração sofrida pelo companheiro como algo natural do relacionamento conjugal. 
Mesmo não reconhecendo a violência no seu cotidiano, a maioria das mulheres em suas falas revelam que as atitudes do marido produzem repercussões sobre sua saúde tais como: cefaléia, nervosismo, depressão, insônia, taquicardia, DST, frigidez, inapetência ou comer compulsivamente, dor de estômago. Muitos desse sinais e sintomas são repetidos entre as entrevistadas após cada discussão ou abuso, como revela essa fala:

\section{Dores de cabeça, nervoso, insônia (Entrevistada 1, 5, 6, 9) \\ Depressão, palpitação, ferimento no corpo (Entrevistada 12) \\ Falta de apetite, doença venérea (Entrevistada 3)}

Assim, a mulher, ao ser admitida numa maternidade por aborto, muitas vezes traz, em sua história de vida, vivência de violência, todo o conflito relacionado com o processo de abortamento. As autoras Heise (1994) e Saffioti (1997) assinalam que estas repercussões vão se manifestando à medida que a mulher se expõe à situação de violência e podem permanecer durante muitos anos, mesmo quando estas se separam dos companheiros.

Ao indagar porque razão estas mulheres permanecem vivendo em situação de violência, a maioria respondeu que a mulher que aceita esta situação é porque gosta de apanhar, gosta de sofrer, tem medo, é dependente do marido ou gosta dele. Lagarde (1990) refere que no cotidiano doméstico a violação a que estão submetidas as mulheres pela norma familiar, não existe como tal, porque não é concebida, caracterizada e reconhecida nessa qualificação, nem pela sociedade, nem pelas vítimas, nem pelos cônjuges. Portanto, ações ocorridas dentro da família são negadas ou minimizadas em sua intensidade, enquanto fora do espaço familiar são reconhecidas e reprovadas como violência e constituem-se em delitos. Estas mulheres falam com certo desprezo das que permanecem em situação de violência, como um fato distante de suas realidades de vida.

Deve ser porque gosta muito dele e não consegue largar. (Entrevistada 3, 5) Eu acho que a mulher gosta de apanhar. (Entrevistada 2, 4, 8, 10,11)

A violência no espaço doméstico pode assumir várias formas e entre as entrevistadas suas respostas demonstraram que estão submetidas a situações de violência emocional (100\%) e violência sexual (75\%) e apenas $25 \%$ admitiram sofrer violência física.

A violência emocional é adotado por Moreira, Ribeiro e Costa (1992) como intimidação, humilhações verbais, manipulações, omissões, abandono e negligência. Ela provoca privação da vontade que resulta em constrangimento, frustrações e insatisfação pessoal. Se caracteriza pela atitude do companheiro quando trata a mulher com menosprezo, fria indiferença, sarcasmo, longos silêncios ou manipulações, chantagem, ameaça, humilhação, destruição de objetos pessoais como forma de amedrontar ou obter obediência da mulher. De forma sutil ele repete a mensagem de que a percepção da mulher sobre a realidade está incorreta. O companheiro fala sempre com autoridade, como dono da verdade, considera seu ponto de vista como único e correto, não dá validade e não valoriza as afirmações da companheira, no entanto com os amigos e família ele se comporta de maneira agradável. A mulher vive um estado de confusão pela mudança de comportamento do homem, em público e no ambiente familiar, sentindo-se cada vez mais frustrada, angustiada, por não conseguir que o companheiro compreenda seus pontos de vista, compartilhe com seus planos e sentimentos. Começa a duvidar de sua própria experiência, sentindo-se culpada pelo que se passa.

No grupo estudado a violência emocional não foi reconhecida como tal, mas, em suas falas, as entrevistadas descrevem viver em situação na qual o companheiro as trata com indiferença quando as ignora como pessoas, não respeita a forma como desejam se vestir, não dá importância ao que elas dizem ou fazem; priva a liberdade quando proíbe de ter amigos e 
receber amigos, proíbe sair de casa, não permite ter uma vida social, só permitindo visitar os pais; controla o que deve vestir rasgando e jogando na rua as roupas que não gosta; intimida através de ameaça física e quebra de objetos dentro de casa; humilha através de palavras depreciativa, do desprezo, quando trata como uma serviçal e ameaça abandoná-la.

Ele goza do que falo, não liga quando eu choro, me compara com outras mulheres. Me trata com indiferença, não me dá carinho. Para ele eu sirvo para cozinhar, lavar, passar e ir para cama quando ele quer." (Entrevistada 1,2)

Quando saio com ele, não posso olhar para o lado, só visto a roupa que ele quer e deixa. Não me deixa ter amigas, diz que agora sou casada e não posso ficar batendo perna. (Entrevistada 5,4,11)

Quebra as coisas dentro de casa, rasga minhas roupas, joga minhas roupas na rua.

(Entrevista 12)

A violência sexual consiste em forçar física ou emocionalmente a mulher a ter relação sexual sem que deseje, sem seu consentimento, obriga a praticar certo tipo de conduta sexual que não queira (Moreira; Ribeiro; Costa, 1992)

Saffioti (1993) refere que a violência sexual acontece a partir do momento em que o homem mantém relações sexuais, contrariando a vontade da mulher, provando assim, sua capacidade de submeter a outra parte, ou seja, aquela que, segundo a ideologia dominante, não tem direito de desejar, não tem direito de escolher. Esta autora refere, ainda, que "há relações amorosas estáveis, legais ou consensuais, no seio das quais o estupro é norma" porque continua vigente no Brasil o chamado "débito conjugal", no qual a mulher tem obrigação de manter relações sexuais com seu cônjuge mesmo quando não deseja. Presas a esse conceito, as mulheres cumprem seu dever, mesmo quando não desejam ter uma relação. Podem até se sentir violentadas, mas se submetem ao marido para evitar que ele procure uma outra mulher (Saffioti, 1997).

As mulheres relatam que seus companheiros criticam o seu desempenho sexual através de palavras depreciativas como "é ruim de cama", "é fria", "é uma geladeira", comparam-nas com outras mulheres; reivindicam seu direito conjugal independente da vontade dela; utilizam a intimidação através da ameaça de abandono ou de procurar outra mulher caso esta se negue a ter relações sexuais; e utilizam violência física ou insistência até a mulher ceder aos seus desejos.

Fucs (1993) refere que a mulher, em sua grande maioria, não se conhece, não assume suas sensações eróticas, porque ela não vivencia sua sexualidade. "Utiliza-a para fins os mais diversos que não o de se gratificar, sentir-se completa, perceber-se como ser humano sadio e perfeito. Sequer tem consciência de que se vê sem direito, só sendo possuidora de deveres sexuais; assim, a força instintiva que carrega dentro de si lhe serve apenas apara agradar e prender o homem (Fucs, 1993, p.21-22)."

Assim, as mulheres falam da relação sexual com um ato de "fazer" e "dar" ao parceiro o que ele quer e não um ato a ser compartilhado.

Eu vivo magoada, quando ele procura querendo sexo, eu não quero. Ele fica falando, brigando, diz que sou uma geladeira. Muitas vezes faço sem vontade só para não ter briga. (Entrevistada 1)

O homem quer sexo todo o dia. Eu não quero, porque tem dia que estou cansada, 
mas ele não entende. Eu queira ou não, tenho que dar. Ele briga, fala alto, me futuca a noite toda sem me deixar dormir, até eu dar. Eu fico zangada e não sinto nada. Fala de homem que arranja mulher na rua. Diz que não tem ninguém e que é minha obrigação. Quando o homem não tem sexo a noite, pela manhã ele amanhece procurando briga. Fala da comida, reclama dos filhos, exige tudo na mão como se eu fosse sua empregada. Eu digo a ele que não sou sua empregada, que sou sua mulher. Ele diz que sou um zero a esquerda. Que não sirvo prá nada. Ai prá viver bem, tenho que dar toda vez que ele quer. (Entrevistada 4)

Ele me forçava a ter relações quando eu não queria. Durante a relação ele me segurava pelo cabelo e me faz chamar pelo nome dos amigos dele como se eu tivesse tendo relações com todos eles. Fica me xingando dos piores nomes. (Entrevistada 11)

A violência física é caracterizada por pancadas, pauladas, mordeduras, queimaduras, feridas com arma de fogo ou faca (Moreira; Ribeiro; Costa, 1992). No relacionamento conjugal a violência física pode surgir de repente, não necessitando justificativa, como pode apresentarse de maneira cíclica, conhecido como ciclo da violência doméstica, que se subdivide em três fases: de tensão, de agressão e de conciliação. A fase de tensão se caracteriza por uma escalada gradual de tensão que se manifesta em atos de irritação e conflitos com companheiro como insatisfação crescente, comportamento hostil, e insultos. A mulher tenta acalmar, não fazer aquilo que possa causar mal-estar, busca descrever qualidades em seu companheiro que gostaria que o mesmo tivesse. A tensão segue aumentando com discussões freqüentes que dará curso aos abusos físicos, sexuais e psíquicos que caracterizam a fase de agressão. Quando o agressor comete a violência, ocorre a redução da tensão anterior. A fase de conciliação é a etapa na qual o agressor se arrepende, pede perdão e mostra consideração com sua vítima e promete que a violência não voltará a se repetir. Este momento provê o reforço positivo para que a mulher se mantenha na relação, acreditando que pode ajudar o companheiro a mudar. Tenta se resignar e justificar a violência vivida atribuindo a causa a algum comportamento seu, inadequado a uma mulher casada, muitas vezes, nem reconhece o que sofre como sendo violência. Modifica seu próprio comportamento como um esforço de alcançar algum nível de controle da situação. Quando não há tensão, não há violência física, permitindo a mulher ver o lado bom do companheiro. Só quando diminui ou desaparece a fase de conciliação, é que a mulher reconhece o companheiro como agressor, sente que tem um problema e busca ajuda. Até chegar este momento podem ter transcorrido vários anos. (González,1996; McFalarne, 1989).

Entre as entrevistadas, apenas três relataram experiências de violência física, mostrando que estas foram precedidas de violência emocional como humilhação, ameaça, xingamentos; que muitas vezes aconteceram sem justificativa, pelo simples fato de chegarem embriagados, outras vezes pelo fato delas reclamarem.

Logo no início quando a gente ficou junto era bom, depois que eu engravidei e tive meu filho ele mudou. Começou a sair, viajar, desaparecia, não colocando comida em casa e os pais dele me ajudam até hoje. Agora engravidei de novo, e eu estou amamentando. Ele não muda. Eu já fiz tudo para tentar viver bem. Eu ainda não consegui ir embora. Ameaça me bater, me humilha, diz que está com amante, que sou maluca. Me empurra e dá tapas. (Entrevistada 5)

Todas as vezes que ele se encontra com a outra mulher, ele diz que é dando assistência a sua filha. Eu fico com ciúme e começo a reclamar e a gente briga e 
ele diz que a culpa é minha. A familia dá todo apoio a ele e não gosta de mim. Eu estou me sentindo muito sozinha. Eu é que provoco as discussões e por algumas vezes ele já me empurrou para eu cair e já me bateu. Algumas vezes ele já me empurrou e me deu tapa. (Entrevistada 11)

Tem 4 anos que ele começou a beber. Antes ele reclamava muito de tudo e me forçava ter relações todos os dias. Quando começou a beber ele começou a me bater. Quando era no outro dia pedia desculpa, dizia que não lembrava de nada, que não ia fazer de novo, passava um dia fazia tudo de novo. Eu larguei ele uma vez, ele foi me buscar. Agora eu tornei largar ele, ele fica atrás de mim, me ameaçando. Eu estou morando na casa de minha irmã. Outro dia ele entrou na casa de minha irmã e me bateu lá. Eu não posso sair de casa. Outro dia me encontrou na rua me jogou pedra, saiu atrás de mim xingando e diz que vai me matar. (Entrevista 12)

\section{OS NEXOS ENTRE VIOLÊNCIA CONJUGAL E O ABORTO PROVOCADO}

Sabe-se que o número de abortos clandestinos praticados no Brasil é desconhecido, em razão da própria ilegalidade do ato. Esta não inibe a sua prática, mas exerce forte influência na relação entre a condição em que o aborto ocorre e a situação socio-econômica da mulher. A mulher de classe social baixa utiliza qualquer procedimento na tentativa de abortar. Geralmente procuram os serviços públicos para realização de curetagem, pois quase sempre o aborto é incompleto.

Entre as maneiras utilizadas pelas mulheres para provocar o aborto estão a ingestão de chá de cravo, chá de hortelã, uso de citotec por via oral e/ou vaginal. Após o uso desses métodos, todas apresentaram abortamento incompleto, acompanhado de hemorragia e contrações sendo internadas e submetidas a curetagens.

Ao tentar descobrir os nexos entre violência e aborto surge o primeiro questionamento; o aborto representa um momento de autonomia da mulher dentro do ciclo da violência?

As entrevistadas relataram as atitudes e reações do companheiro e da família diante da gravidez que variaram de sentimento de raiva, rejeição da paternidade, atribuição à mulher da total responsabilidade pelo controle contraceptivo, pela falha na contracepção e eliminação do feto; acusação, indiferença, abandono, agressão física, negligência no sustento familiar, preocupação com a condição financeira.

\section{Dificuldades econômicas}

Entre as entrevistadas a decisão pelo aborto provocado é justificada, em primeiro lugar, devido às dificuldades econômicas, associadas à própria dependência financeira vivida por ela, a irresponsabilidade do companheiro na provisão da família.

A dependência financeira e conseqüente subordinação desperta na mulher o desejo de trabalhar como possibilidade de igualar-se ao companheiro quanto à liberdade e independência financeira, de maneira que possa haver mais equilíbrio no relacionamento conjugal. Assim, no cotidiano dessas mulheres, a gravidez potencializa as dificuldades financeiras e intensifica os conflitos como também a gravidez representa o adiamento por mais tempo da liberdade sonhada. O aborto se apresenta, segundo este ponto de vista, como um momento de autonomia da mulher, pela possibilidade de realizar seus projetos de vida.

Nessa fala a entrevistada aponta o trabalho como uma forma de suprir as necessidades da família, pelo desejo de ser socialmente útil e de conquistar uma certa independência em relação ao marido: 
Já tenho um filho, as condições não estão permitindo. Ele não está assumindo as responsabilidades. Eu trabalho, mas meu salário não dá e não tenho quem tome conta de meu filho. Ele nem sabe que abortei, mas eu tenho que cuidar de mim. Pelo gosto dele eu paria um todo ano. Só pode ser para eu ficar presa dentro de casa cuidando de filho e ele na rua se divertindo. Senti aliviada, porque não podia ter esse filho agora. Comecei a trabalhar e preciso me libertar. Se não for agora, vou ficar presa, cuidando de filho e sofrendo com marido. (Entrevistada 1)

Esse discurso demonstra que a sexualidade e o controle da reprodução não é algo compartilhado, mas uma situação unilateral em que o homem vê a mulher no papel de satisfazêlo sexualmente e de tomar as providências da contracepção

Eu já tenho três filhos, a situação não está boa e eu não tenho mais idade para parir. Ele também disse que não queria mais filho, que a culpa é minha, que eu desse um jeito. Aí ele comprou Citotec e eu tomei. Não é fácil fazer isso. A mulher se torna uma assassina, mata seu próprio filho. Eu não pude comprar o anticoncepcional esse mês, ele não se conforma em usar camisinha. É duro, saber que o homem não compreende e depois a gente tem que assumir o aborto sozinha. (Entrevistada 4)

A gravidez é percebida pela mulher como uma forma que o homem utiliza para manté-la presa em casa e o aborto representa uma forma de preservar sua liberdade.

Estou com um filho pequeno que só faz mamar. Estou passando necessidade, completamente presa, dependendo sempre dele. Se eu parisse outro filho agora sei que não voltaria a trabalhar. Ele está cada vez mais independente, se importando muito pouco comigo. Preciso trabalhar e cuidar de minha vida. "Eu procurei uma mulher porque estava decidida. Ele não sabe que abortei e eu não vou dizer. Não parei nem para pensar o que sinto com o aborto, mas precisava fazer e também preciso me cuidar. (Entrevistada 7)

\section{Violência física}

Como segunda justificativa as mulheres referem que a gravidez não faz cessar as agressões físicas que vêem sofrendo, ao contrário, estas aumentaram em freqüência e intensidade como referem McFarlane et al.(1992), Helton e Mcfarlane. (1987), Valdez; Sanin (1996).

Dentre as razões apontadas pelas mulheres que influenciaram na decisão pelo aborto encontra-se: a instabilidade conjugal devido a discussões freqüentes; a indiferença por parte do companheiro; a recusa do parceiro em assumir a patemidade e a mulher não ter como perspectiva a maternidade sozinha, como, também, a incerteza dos sentimentos em relação ao parceiro, mesmo quando este se dispõe a assumir a paternidade ou união; a exposição à violência física; a coação por parte do companheiro através da compra do Citotec.

Cardich e Carrasco (1993) afirmam que,entre as razões que levam a mulher a abortar, está presente a violência quando a mulher é intimidada, forçada ou agredida pelo companheiro ou familiares, devido à dependência emocional ou econômica e, por estar em situação de violência renuncia à sua liberdade e sua vontade, como forma de diminuir o sofrimento ou reage abortando como forma de punir o companheiro pelo tratamento que vem recebendo por parte deste.

Eu tomei um chá para a menstruação descer. Estava atrasada três meses, eu disse para ele que estava com um bolo na barriga e assim mesmo ele continuou 
a me bater. Ele disse que não queria filho nenhum. Eu queria meu filho, ele é o culpado. (Entrevistada 5)

Com tudo isso que já contei, eu já tenho dois filhos e não podia parir mais esse. Olhe aqui, eu estou toda marcada, de pancada que tomei agora com dois meses de gravidez. Eu sair de casa e abortei. Eu não estou sentindo nada. Eu quero ficar livre de tudo isso. Estou anestesiada. (Entrevistada 12)

O discurso da entrevistada 6 descreve as pressões emocionais e a intimidação por parte do companheiro obrigando-a abortar.

Meu marido disse que não queria o filho. Eu fiz ultrassonografia e deu que era menino e ele disse que não quer filho homem, só filha. Aí eu fiz o que ele quis. Ele comprou e eu tomei Citotec. Prá que procurar confusão, se a gente vive bem? (Entrevistada 6)

A entrevistada 8 em sua fala sente-se satisfeita com o sentimento de culpa do companheiro e o aborto torna-se uma forma de punir os companheiros pelo tratamento que vem recebendo:

No domingo ele saiu pela manhã e chegou 1:00 da madrugada. Disse que estava jogando bola. Quando ele entrou eu estava chorando. Nós brigamos, ele disse que eu não tinha nada com a vida dele. Fiquei com raiva, porque eu estava grávida e nem isso fez ele melhorar. Eu tirei o DIU para fazer a vontade dele, que queria outro filho. Então tomei Citotec e não disse nada prá ele. Ontem, quando começou a dor, eu sai de casa e vim para o hospital. Ele só veio saber depois que fiz a curetagem. Quando soube do aborto, veio aqui no hospital e começou a chorar. Ele não sabe que tomei remédio, ele pensa que foi por causa da briga e está todo arrependido. Não é fácil para uma mulher saber que está matando seu filho. Porém eu sabia que seria mais um filho que cuidaria sozinha, porque nada faz ele mudar. Para ter outro filho ele vai ter que provar que mudou, se não, nunca mais vou parir um filho dele. (Entrevistada 8)

Outro filho agora seria uma desgraceira. Não vou agüentar muito tempo. Estou pensando em ir embora para casa de meus pais e seria dificil ficar com dois filhos. Eu tomei chá de hortelã bravo e comecei a ter hemorragia. Eu me arrependi, mas eu acho que quando uma mulher faz isso não pode ficar pensando muito. (Entrevistada 10)

Eu já tenho uma filha e ele também tem uma. Eu só quero um filho se eu ficar com ele. A gente sente uma tristeza em fazer isso e eu acho que a culpa não é minha só. Me deu uma raiva dele, por ter que fazer o aborto, porque ele não quis o meu filho. Mas também sozinha eu não vou assumir. (Entrevistada 11)

\section{CONSIDERAÇÕES FINAIS}

As mulheres investigadas em sua vivência no cotidiano doméstico, estão sujeitas a todas as formas de manifestações de violência, apesar de reconhecerem como tal, apenas a violência física. A violência emocional esteve presente entre todas as mulheres, que a consideram como fato natural no relacionamento, mesmo isto trazendo mal estar e repercussões para sua saúde.

O profissional de saúde para entender o que significa para a mulher a experiência do 
aborto, é necessário não percebê-lo apenas sobre a ótica sócio-econômica ou como um evento da vida reprodutiva, mas também deve ser considerada a vida afetiva da mulher no momento em que se deu o evento do aborto. Muitas delas não contaram aos companheiros, optando por decidir sozinhas pelo aborto, que foi descrito como uma experiência difícil, estando presentes sentimentos ambíguos, que variam da tristeza, frustração, culpa e revolta por ser forçada pelo companheiro a abortar, medo pela sua própria vida e alívio por solucionar o problema de uma gravidez indesejada. Verificamos que esta vivência de violência conjugal cria um ambiente hostil com aumento progressivo de tensão que pode ter influenciado as mulheres na decisão de abortar. Porém acreditamos ser necessárias maiores investigações sobre o tema.

ABSTRACT:Studies on marital violence against women have contributed to a better understanding of the health problems to which this population is exposed to, especially those related to reproduction. The need to investigate more deeply connections between home violence and provoked abortion has elicited questions like: "Does the decision to abort occur during the violence cycle as a moment of autonomy for the woman or is she forced to do it? The purpose of this qualitative study is to describe manifestations of marital violence among women admitted to the hospital due to provoked abortions, analyzing the influence of such violence on their decision to have an abortion. With the results, the study intends to broaden the discussion on home violence and abortion, giving visibility to these problems in the context of health services.

KEYWORDS: marital violence, provoked abortion, violence cycle

RESUMEN: Los estudios sobre la violencia conyugal contra la mujer han taído importantes contribuciones para la comprensión de los problemas de salud, a los que esta población está expuesta, en especial los a la actividad reproductiva. La necesidad de investigar en profundidad los nexos entre la violencia y el aborto provocado ha generado algunos planteamientos, por ejemplo: ¿Será que la decisión de abortar surge en el ciclo de la violencia conyugal como un momento de autonomía de la mujer o estas son forzadas a practicar el aborto? Este estudio cualitativo tiene como objeto caracterizar las manifestaciones de la violencia conyugal entre las mujeres internadas en situación de aborto provocado y analiza la influencia que tiene la violencia sobre la decisión de abortar. Se pretende con los resultados ampliar la discusión sobre la violencia y el aborto dando visibilidad a esos problemas en el ámbito de los servicios de la salud. También posibilita la reflexión de las mujeres sobre la situación a que están sometidas, mediante una discusión colectiva de sus historias de vida que reflejen amenazas, desamor, negligencia, violencia sexual y agresión física.

PALABRAS CLAVE: violencia conyugal, aborto provocado, ciclo de la violencia

\section{REFERÊNCIA BIBLIOGRÁFICAS}

CARDICH, Rosário; CARASCO, Frescia. Visiones del aborto: nexos entre sexualidad anticoncepción y aborto. Lima: Movimento Manuela Ramos the Population Council, 1993.

FUCS, Gilda Bacal. Homem-mulher: encontros e desencontros. 2. ed. Rio de Janeiro: Rosa dos Tempos, 1993

GÓMES, Adriana. Violencia contra las mujeres: un ejercicio de poder. Caderno Mujer Salud, Chile, Red Salud de las Mujeres LatinoAmericanas y del Caribe (RSMLAC), n. 1,1996.

GONZÁLES, Nirvana. Violencia doméstica: el ciclo perverso, Caderno Mujer Salud, Chile, Red Salud de las Mujeres LatinoAmericanas y del Caribe (RSMLAC), n. 1, 1996. 
HEISE, Lori. Gender-based abuse: the global epidemic. Cadernos de Saúde Pública, v.10, p.135145,1994. Suplemento 1.

HELTON, Anne Stewart; MCFARLANE, Judith; ANDERSON, Elizabeth. Battered and Pregnant: a prevelence study, AMJ Public Health, v.77,n.10, p.1337-1339,1987.

LAGARDE, Marcela. Los cautiveiros de las mujeres: madresposas, monjas, putas, presas y locas, México: Coordinación General de Estudios de Posgrado, UNAM, 1990

MCFARLANE Judith. Battering during pregnancy: tip of na iceberg revealead. Women \& Health, v. 15, n.3, p.69-81, 1989.

MCFARLANE Judith et al. Assessing for abuse during pregnancy: severity aud frequency of injuries and associated entry into prenatal care. JAMA, n.267, p.176-8, 1992.

MOREIRA, Maria I. C.; RIBEIRO, Sonia F.; COSTA, Karine F. Violência contra a mulher na esfera conjugal: jogos de espelhos In: Entre a virtude e o pecado. Rio de Janeiro: Rosa dos Tempos, São Paulo: Fundação Carlos Chagas, 1992.p.169-189.

NORONHA, Ceci Vilar; DALTRO, Maria Esther. A violência masculina é dirigida para Eva ou Maria? Cad.Saúde Pública, ENSP/RJ, v.7, n.2, p.201-214, 1991.

PAVEZ, Graziela Acquaviva. Expressões da violência: violência doméstica. In: D'OLIVEIRA, Ana Flávia Lucas. (Org) Coletânea de textos para curso de Capacitação para Atendimento a Mulheres em Situação de Violência. São Paulo: DMP/FMUSP/CFSS, 1995.

SAFFIOTTI, Heleiete I. B. O poder do macho. 7.ed. São Paulo: Moderna, 1993.

Violência de gênero no Brasil contemporâneo. In: SAFFIOTI, H. I. B.; MUNOZ-VARGAS, M. Mulher Brasileira é assim. Rio de Janeiro: Rosa dos Tempos, 1994. p. 151-186.

Violência doméstica ou a lógica do galinheiro. In: KUPSTAS, Márcia (Org.). Violência em debate. 11.ed. São Paulo: Moderna, 1997. (Coleção polêmica. Série debate na escola).

SOUZA, Vera Lúcia Costa. A problemática do aborto em Feira de Santana-Bahia. Sitientibus, UEFS, n. 19, p.9-26, jul./dez. 1998.

VALDEZ, Rosario Santiago; SANÍN, Luz Helena Aguire. La violencia doméstica durante el embarazo su relación com el peso al nacer. Revista Salud Publica México, n.38, p. 352-362, 1996.

\footnotetext{
Recebido em agosto de 2000

Aprovado em março de 2001
} 